\title{
Renal ${ }^{|3|}$ I-hippuran extraction in man: effects of dopamine
}

\section{Hutchings,' B. Hesse, ${ }^{2}$ J. Grønvall ${ }^{3}$ \& N. V. Olsen ${ }^{1,4}$}

Departments of ${ }^{1}$ Neuroanaesthesia, The Neuroscience Centre, ${ }^{2}$ Clinical Physiology and Nuclear Medicine, The Diagnostic Centre, ${ }^{3}$ Radiology, Cardiovascular unit, The Diagnostic Centre, Copenhagen University Hospital (Rigshospitalet), and ${ }^{4}$ Department of Pharmacology, Panum Institute, University of Copenhagen, Denmark

\begin{abstract}
Aims This study examined the ${ }^{131}$ I-hippuran extraction fraction during baseline renal blood flow rates and at high flow rates induced by dopamine.

Methods In 12 healthy subjects, arterial and renal venous sampling was used to measure the renal extraction of ${ }^{131}$ I-hippuran. Effective renal plasma flow values determined by the urinary clearance of ${ }^{131}$ I-hippuran were compared with renal plasma flow values corrected for incomplete extraction of ${ }^{131} \mathrm{I}$-hippuran.

Results Dopamine $\left(3 \mu \mathrm{g} \mathrm{kg}^{-1} \mathrm{~min}^{-1}\right)$ decreased ${ }^{131}$ I-hippuran extraction from $75 \pm 4 \%$ at baseline to $62 \pm 6 \%$ (means $\pm 95 \%$ confidence intervals, $P<0.001$ ). Hence, the increase in renal plasma flow $(85 \pm 23 \%)$ greatly exceeded the rise in effective renal plasma flow $(51 \pm 15 \%, P<0.002)$.

Conclusions Dopamine induced increases in renal blood flow are largely underestimated when measurements are not corrected for incomplete extraction of ${ }^{131}$ I-hippuran.
\end{abstract}

Keywords: ${ }^{131}$ I-hippuran, effective renal plasma flow, iodohippuric acid

\section{Introduction}

${ }^{131}$ I-hippuran and para-aminohippurate (PAH) are eliminated by glomerular filtration and tubular secretion, and at low plasma concentrations they are excreted almost completely during the first passage through the kidneys [1]. Thus, renal plasma flow (RPF) can be determined according to Fick's principle:

$$
\begin{aligned}
\mathrm{RPF}= & \text { Excretion rate of } \mathrm{PAH} /[\mathrm{PAH}] \text { renal arterial } \\
& \text { plasma }-[\mathrm{PAH}]_{\text {renal venous plasma }}
\end{aligned}
$$

Assuming a complete renal extraction of PAH $\left([\mathrm{PAH}]_{\text {renal venous plasma }}=0\right)$ and equal steady state concentrations of PAH in systemic venous and arterial plasma (including renal arterial plasma), RPF can be measured as the renal clearance of PAH $\left(\mathrm{C}_{\mathrm{PAH}}\right)$ :

$$
\begin{aligned}
\mathrm{RPF}= & \text { Excretion rate of } \mathrm{PAH} /[\mathrm{PAH}] \text { systemic venous } \\
& \text { plasma }=\mathrm{C}_{\mathrm{PAH}},
\end{aligned}
$$

mostly referred to as the effective renal plasma flow (ERPF).

Correspondence: Dr N. V. Olsen, Department of Neuroanaesthesia 209I, The Neuroscience Centre, Copenhagen University Hospital (Rigshospitalet), 9 Blegdamsvej, DK 2100 Copenhagen, Denmark. Tel.: + 45 353276I8; Fax:+ 45 35327610; E-mail: fino@farmakol.ku.dk

Received 9 April 2002, accepted 13 June 2002.
ERPF has been widely used to evaluate changes in renal blood flow in various pathophysiological states and in response to pharmacological interventions. The use of ${ }^{131}$ I-hippuran as an alternative indicator has gained preference because its specific activity in plasma and urine is more easily measured than the concentration of nonisotopic $\mathrm{PAH}$.

However, the renal extraction of PAH and ${ }^{131}$ I-hippu$\operatorname{ran}\left(\mathrm{E}_{\mathrm{PAH} / \mathrm{Hip}}\right)$ is lowered during diseases associated with decreases in renal function [2] and by pharmacological interventions that increase renal blood flow [3]. Hence, measurement of ERPF by the renal clearance of ${ }^{131}$ Ihippuran or PAH implies a systematic underestimation of the renal plasma flow. This can only be corrected for by sampling of blood from the renal vein.

The aim of this study was to determine $\mathrm{E}_{\mathrm{Hip}}$ in healthy individuals during baseline renal blood flow rates and at high flow rates induced by low-dose dopamine. Besides being the most efficacious renal vasodilatating drug known thus far, dopamine also remains as one of the drugs of choice for the treatment of low cardiac output states. Earlier studies in dogs [4] and in hypertensive patients [5] indicated that dopamine decreases $\mathrm{E}_{\mathrm{PAH}}$, but the effect of dopamine on $\mathrm{E}_{\mathrm{Hip}}$ in normal man remains unknown. The setup including renal venous catheterization allowed reevaluation of the well established increase in ERPF during dopamine infusion [6]. 


\section{Methods}

Twelve healthy male volunteers aged 23-38 (mean $26 \pm$ years) entered the study after having given their written, informed consent.

Each subject had an arterial cannula inserted in the left radial artery, peripheral venous catheters in both cubital regions, and finally a catheter in the left renal vein $(5 \mathrm{~F})$, introduced via the right femoral vein. The position of the renal venous catheter (lateral to the junction with the testicular vein) was confirmed radiologically and then every $30 \mathrm{~min}$ by measurements of renal venous oxygen saturation. After a $1 \mathrm{~h}$ baseline period, an intravenous infusion of dopamine $\left(3 \mu \mathrm{g} \mathrm{kg}^{-1} \mathrm{~min}^{-1}\right)$ was given for $2 \mathrm{~h}$.

ERPF, RPF and $\mathrm{E}_{\mathrm{Hip}}$ at baseline and during the second hour of the dopamine infusion were measured by a constant infusion technique and with timed urine collections, using ${ }^{131}$ I-hippuran given as an intravenous bolus (0.33 $\mathrm{MBq})$ followed by continuous infusion (0.011 MBq $\left.\mathrm{min}^{-1}\right)$ [6].

One subject had to be omitted because of unwanted side-effects of dopamine (nausea) and one was omitted due to analytical problems. Data were analysed by paired Student's $t$-tests. All results are expressed as means $\pm 95 \%$ confidence intervals.

\section{Results}

ERPF increased during dopamine infusion by $51 \pm 15 \%$ $(P<0.001)$ whereas RPF increased by $85 \pm 23 \%$ $(P<0.001$, Figure 1). This difference between RPF and ERPF increases was highly significant.

At baseline, the extraction fraction of ${ }^{131}$ I-hippuran was $75 \pm 4 \%$, ranging from 54 to $84 \%$ (Figure 2). During dopamine infusion, the extraction fraction decreased to $62 \pm 6 \%$, ranging from 39 to $73 \%$.

\section{Discussion}

Several studies using the renal clearance of PAH or ${ }^{131} \mathrm{I}-$ hippuran have demonstrated that an infusion of low doses of dopamine in normal humans consistently produces a 30-60\% increase in ERPF [6]. The present results show that the increase in total renal plasma flow is associated with a marked decrease in $\mathrm{E}_{\mathrm{Hip}}$. Thus, dopamine induced increases in renal perfusion are largely underestimated when based on ${ }^{131}$ I-hippuran clearance measurements that are not corrected for incomplete extraction of ${ }^{131}$ I-hippuran.

Even in baseline conditions, $\mathrm{E}_{\mathrm{Hip}}$ only averaged $75 \%$. This is well below the values of around $90 \%$ for $\mathrm{E}_{\mathrm{PAH}}$ that have been measured previously in healthy individuals $[2,3]$. When based on measurements of ERPF, the low $\mathrm{E}_{\text {Hip }}$ in our subjects resulted in an underestimation of baseline values of the true renal plasma flow by on
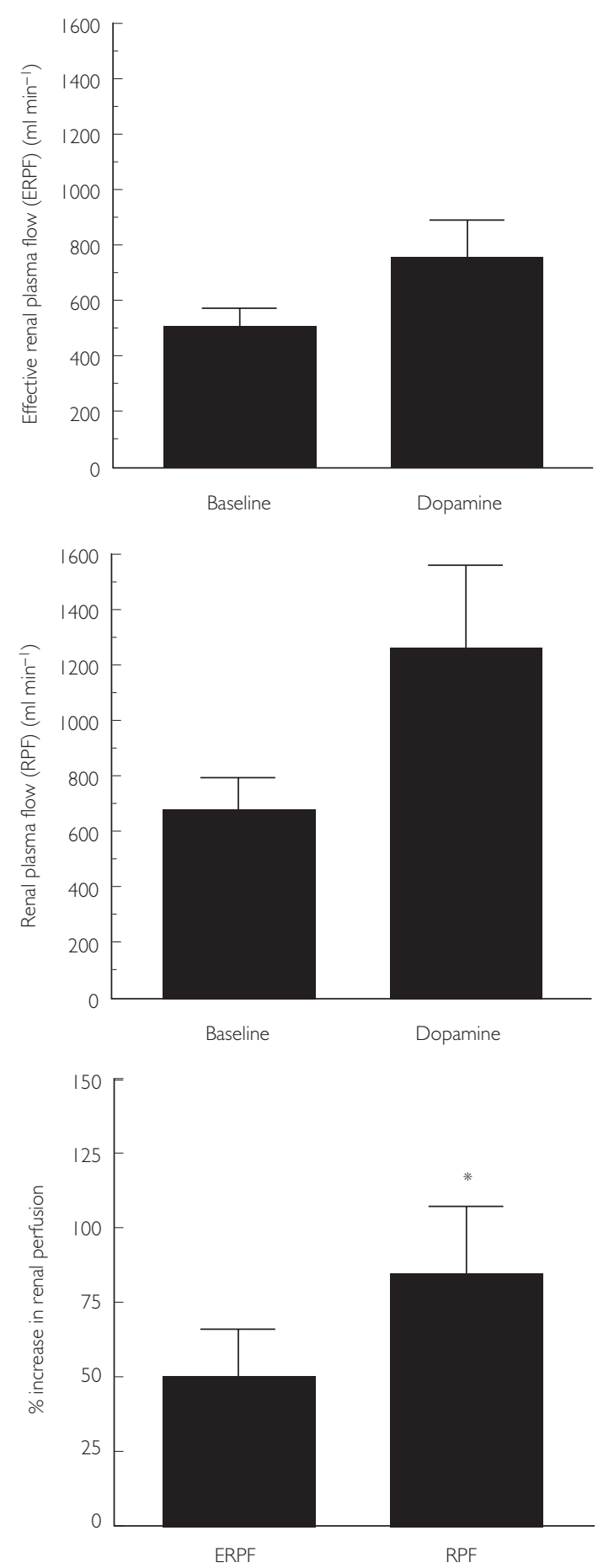

Figure 1 Dopamine induced effects on renal perfusion when assessed without (effective renal plasma flow) and with correction for incomplete extraction of ${ }^{131}$ I-hippuran (renal plasma flow). Significance of differences: ${ }^{\star} P<0.002$ compared with ERPF. Both methods revealed a highly significant increase in renal perfusion $(P<0.001)$. 


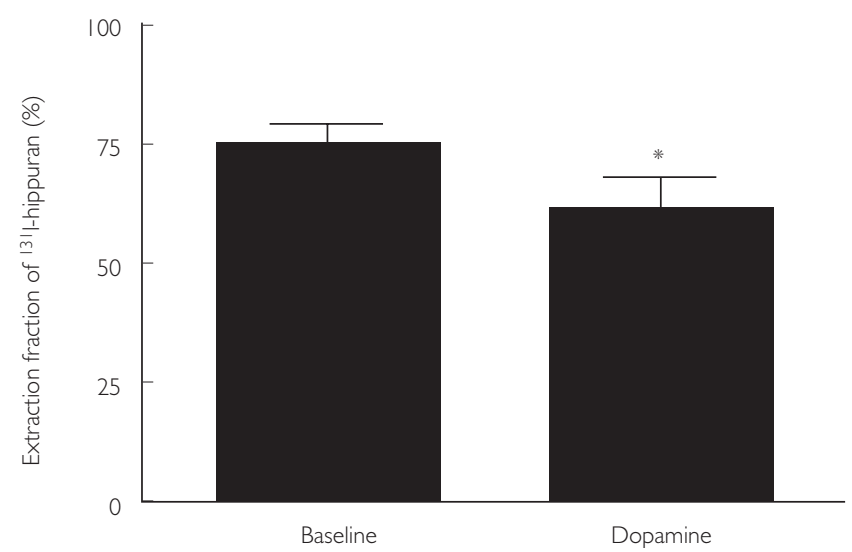

Figure 2 Effects of dopamine infusion $\left(3 \mu \mathrm{g} \mathrm{kg}^{-1} \mathrm{~min}^{-1}\right)$ on the fractional renal extraction of ${ }^{131}$ I-hippuran. Significance of differences: ${ }^{\star} P<0.001$ compared with baseline.

average $26 \%$. In patients with diabetic nephropathy, Battilana et al. observed that the renal clearance of ${ }^{131} \mathrm{I}-$ hippuran was only $75 \%$ of the PAH clearance, indicating a less efficient renal extraction of ${ }^{131}$ I-hippuran than of $\mathrm{PAH}$ in these patients [2]. It remains unknown whether such a difference in renal extraction between the two markers also exists in normal humans. Nonetheless, our data emphasize the need for renal venous sampling and determination of $\mathrm{E}_{\mathrm{Hip}}$ to obtain accurate measurements of renal plasma flow by ${ }^{131}$ I-hippuran clearance, even in healthy subjects investigated at normal physiological conditions.

Dopamine has previously been shown to decrease $\mathrm{E}_{\mathrm{PAH}}$. In seven hypertensive patients with unilateral renal disease, infusions of 1-2 $\mu \mathrm{g}$ dopamine $\mathrm{kg}^{-1} \mathrm{~min}^{-1}$ reduced mean values of $\mathrm{E}_{\mathrm{PAH}}$ from $84 \%$ to $72 \%$ [5]. In dogs, a higher dose of dopamine $\left(6 \mu \mathrm{g} \mathrm{kg}^{-1} \mathrm{~min}^{-1}\right)$ reduced $\mathrm{E}_{\mathrm{PAH}}$ by $8 \%$ [4]. Other renal vasodilating drugs may have a similar effect on $\mathrm{E}_{\mathrm{PAH}}$ [3]. Most probably, the fall in $\mathrm{E}_{\mathrm{PAH}}$ produced by these drugs is secondary to changes in the intrarenal distribution of blood flow. Similar to other renal vasodilators, dopamine has been demonstrated to cause a relatively higher increase in the blood flow to the inner renal cortex and the medulla than to the outer cortex [6]. The former areas of the kidney have the lowest extraction of PAH [3] and, presumably, also of ${ }^{131}$ I-hippuran.

In conclusion, low doses of dopamine in normal subjects result in a marked reduction of $\mathrm{E}_{\mathrm{Hip}}$. Even in healthy subjects studied under normal physiological conditions, renal venous sampling and determination of $\mathrm{E}_{\mathrm{Hip}}$ is necessary for accurate measurements of renal plasma flow.

This study was supported by grants from The Danish Medical Research Council, Eva and Henry Fraenkel's Memorial Foundation and The Danish Society of Nephrology.

\section{References}

1 Smith HW, Finkelstein N, Aliminosa L, Crawford B, Graber $\mathrm{M}$. The renal clearances of substituted hippuric acid derivatives and other aromatic acids in dog and man. J Clin Invest 1945; 24: 388-404.

2 Battilana C, Zhang HP, Olshen RA, Wexler L, Myers BD. $\mathrm{PAH}$ extraction and estimation of plasma flow in diseased human kidneys. Am J Physiol 1991; 261: F726-F733.

3 Dworkin LD, Brenner BM. The renal circulations. In The Kidney, ed. Brenner BM. Philadelphia: WB Saunders Company, 1996: 247-285.

4 Meyer MB, McNay JL, Goldberg LI. Effects of dopamine on renal function and hemodynamics in the dog.J Pharmacol Exp Ther 1967; 156: 186-192.

5 Breckenridge A, Orme M, Dollery CT. The effect of dopamine in renal blood flow in man. Eur J Clin Pharmacol 1971; 3: 131-136.

6 Olsen NV. Effects of dopamine on renal haemodynamics, tubular function and sodium excretion in normal humans. Dan Med Bull 1998; 45: 282-297. 